\title{
Der experimentelle Nachweis des magnetischen Moments des Silberatoms.
}

Von W. Gerlach und O. Stern in Frankfurt a. M.

(Vorläufige Mitteilung.)

(Eingegangen am 18. November 1921.)

Vor kurzem hat der eine von uns einen Weg zur experimentellen Prüfung der Richtungsquantelung aufgezeigt ${ }^{1}$ ). Die dort erwähnten experimentellen Untersuchangen müssen aus äußeren Gründen vorübergehend unterbrochen werden. Es sei uns daber gestattet, im folgenden kurz das bisher sichergestellte Ergebnis mitzuteilen, da es uns bereits von hinreichendem Interesse zu sein scheint.

Ein Silberatomstrahl von $1 / 20 \mathrm{~mm}$ Durchmesser geht in hohem Vakuum $\left(10^{-4}\right.$ bis $\left.10^{-5} \mathrm{~mm} \mathrm{Hg}\right)$ hart an der Kante des schneidenförmigen Polschuhs eines Elektromagneten [Halbringelektromagnet nach $d u$ Bois $\left.{ }^{2}\right)$ ] vorbei. Der Strahl kommt aus einem kleinen $\left(1 / 2 \mathrm{~cm}^{3}\right.$ Inbalt), elektrisch geheizten, stählernen Öfchen durch eine im Deckel befindliche, $1 \mathrm{~mm}^{2}$ große, kreisförmige Öffnung. Der Ofen ist von einem wassergekühlten Mantel nmgeben. Etwa $1 \mathrm{~cm}$ vom Ofenloch entfernt passiert er die erste kreisförmige Blende $(1 / 20 \mathrm{~mm}$ Durchmesser) in einem Platinblech. $3 \mathrm{~cm}$ hinter dieser passiert er eine zweite, ebensolche Blende, die sich am vorderen Eude des Schneidenpols des Elektromagneten befindet. $\mathrm{Er}$ geht von hier ab längs der $3 \mathrm{~cm}$ langen Polschneide und trifft an ihrem anderen Ende auf ein Glasplättchen. Die dort niedergeschlagene Silberschicht ist auch bei achtstïndiger Dauer des Versuchs weit unter der Grenze der Sichtbarkeit. Sie wird durch Niederschlagen von naszierendem Silber entwickelt, wobei die geometrische Form des ursprünglichen Niederschlags erhalten bleibt ${ }^{3}$ ).

1) 0. Stern, ZS. f. Phys. 7, 249. 1921. In dieser Arbeit befindet sich ein Irrtum auf S.252 unten. Im klassischen Fall ergibt sich das Intensitätsmaximum an der Stelle des ursprünglichen Flecks nicht für jede einheitliche Geschwindigkeit, sondern erst durch Berücksichtigung der Maxwell schen Geschwindigkeitsverteilung. Eine einheitliche Geschwindigkeit ergibt einen Streifen konstanter Intensität. An den l. c. gefundenen Resultaten ändert sich hierdurch nichts. St.

2) Der Firma Hartmann und Braun sclulden wir herzlichen Dank für die leihweise Überlassung des Elektromagneten.

3) Näheres über Entwicklungsmetbodik usw. wird in einer späteren Notiz mitgeteilt werden. 
Es wurden in abwechselnder Folge neun Versuche gemacht, fünf ohne Magnetfeld, vier mit Magnetfeld. Je ein Versnch ohne und mit Feld ergab gar keinen Niederschlag, einmal aus unbekannten Gründen (Hindernis im Strablengang?), einmal wegen Verstopfung der vorderen Blende durch aus dem Öfchen herausgespritztes geschmolzenes Silber. Die übrigen vier Versuche ohne Feld ergaben einen der geometrischen Dimensionen der Anordnung entsprechenden runden Fleck von etwa $1 / 10 \mathrm{~mm}$ Durchmesser. Die drei Versuche mit Magnetfeld ergaben einen in Richtung $\frac{\partial{ }^{2}}{\partial z}{ }^{1)}$ auseinandergezogener Fleck von ${ }^{1},{ }_{10} \mathrm{~mm}$ Höhe und 0,25 bis $0,3 \mathrm{~mm}$ Länge. Intensitätsstruktur innerbalb dieses Bandes ist noch nicht mit Sicherheit zll erkennen. Der Betrag der beiderseitigen Verbreiterung entspricbt ungefähr einem magnetischen Moment des Silberatoms von 1 bis 2 Bohrschen Magnetonen. Genanere Angaben sind vorlänfig nicht möglich, einmal, weil es noch nicht gelungen ist, das $\frac{\partial \mathfrak{g}}{\partial z}$ so nahe der Schneide zu messen, zweitens, weil wir noch nicht wissen, welche Silberdicke darch die Entwicklung noch nachgewiesen wird. Nach unseren bisherigen Erfahrungen zweifeln wir nicht daran, durch Versache mit Strahlen kleineren Durchmessers and eventnell einer verbesserten Entwicklungsmethodik die Entscheidung anch über die Richtnngsquantelungen treffen zn können.

Das Ergebnis dieser Arbeit ist der Nachweis, daß das Silberatom ein magnetisches Moment hat.

Wir möchten auch an dieser Stelle der Firma Messer a. Co., Luftverflüssigungsanlagen, G. m. b. H. in Frankfurt a. M., unseren herzlichsten Dank aussprechen für die kostenlose Uberlassung der großen Mengen flüssiger Luft.

Frankfurt a. M., 14. November 1921.

1) 1. c., S. 251 . 